\title{
A Contrastive Study of English and Chinese Temporal Metaphors from the Perspective of Culture
}

\author{
Cheng Chen ${ }^{1}$ \\ ${ }^{1}$ School of Foreign Languages, Zhejiang Gongshang University, Hangzhou, Zhejiang, China \\ Correspondence: Cheng Chen, School of Foreign Languages, Zhejiang Gongshang University, Xiasha Higher \\ Education Park, Hangzhou 310018, Zhejiang, China. Tel: 86-139-5714-4993. E-mail: \\ Chencheng_shania@163.com
}

Received: August 20, 2013 Accepted: November 22, 2013 Online Published: January 16, 2014

doi:10.5539/res.v6n1p46

URL: http://dx.doi.org/10.5539/res.v6n1p46

This essay is supported by Project of Zhejiang Department of Education in 2013, China. Project number: Y201327364.

\begin{abstract}
Time is an abstract concept which is invisible and intangible. The traditional framework of contrastive studies of English and Chinese temporal metaphors are at three basic levels-"spatial metaphors", "ontological metaphors" and "structural metaphors". However, this framework is obscure in boundaries and overlapping in areas. Therefore, on the basis of rhetorics, this research is carried out in a novel framework from the perspective of culture on six aspects: 'personalized temporal metaphors', 'materialized temporal metaphors', 'event temporal metaphors', 'abstracted temporal metaphors', 'colorized temporal metaphors' and 'allusion temporal metaphors'. Furthermore, based on the linguistic phenomenon, the cultural implications of temporal metaphors are revealed.
\end{abstract}

Keywords: contrast, English and Chinese, temporal metaphors, culture

\section{Introduction}

Based on Lakoff and Johnson's metaphorical theory (1980, 1999), Contrastive Studies of English and Chinese Temporal Metaphors were carried out from three aspects commonly: "spatial metaphors", "ontological metaphors" and "structural metaphors". Such a classification is on the foundation of conceptual system. "Spatial metaphors" refer to the type of metaphor organizing a concept with a spatial concept such as 'up' and 'down', 'right' and 'left'. "Ontological metaphors" refer to the type of metaphor comparing the abstract concept to the concrete concept. (Lakoff, 1990, 1993) For example, in Mind is a machine., the abstract concept 'mind' is taken as a tangible 'machine' and the thinking can be operated just like the running machine. "Structural metaphors" refer to the type of metaphor constructing an unknown concept with a known concept to overlap the two. For example, Life is a journey can be reflected in the two daily used sentences: "Our partner didn't last. In the end we agreed to go our separate ways.", "I seem to be at a crossroads in my present job". However, the classification of "ontological metaphors" and "structural metaphors" is with obscure and strained definition for the two ones and with overlapping areas. For example, both the "ontological metaphors" and "structural metaphors" can be categorized as "metaphor an unknown concept with a familiar one" as the definition of "structural metaphors" claimed. Moreover, it is not reasonable and scientific to place the "structural metaphors" in the same category with "spatial metaphors" and "ontological metaphors" from the conceptual system foundation, because "space" and "substance" which are both concrete entities in parallel arrangement cannot be collocated at the same level with "structure". 'Metaphor', as an imaginative way, is to describe the abstract thing with concrete thing in order to show that the two things have the same qualities and to make a more powerful description. "Space" and "substance" are both concrete, but "structure" itself is abstract and difficult to explain the ontology. Therefore, on the basis of the weak points of existed researches, this essay makes comparison and contrast of English and Chinese temporal metaphors with innovative classification and analytic frame from the perspective of culture including six aspects: 'personalized temporal metaphors', 'materialized temporal metaphors', 'event temporal metaphors', 'abstracted temporal metaphors', 'colorized temporal metaphors' and 'allusion temporal metaphors', which is categorized from the concrete and classical life experience. The illustrations for each metaphorical aspect are representative and most commonly used language examples in 
English and Chinese, which can mirror the temporal usages in the two languages. The instances are not exhaustive, as they are designed to employ to put forward two trends of distinctive features in Chinese and English. As "language cannot live without culture" (Sapir \& Irvine, 2002), so further explorations are made on cultural enlightenments from English and Chinese temporal metaphor concepts and representations.

\section{Comparison and Contrast of English and Chinese Temporal Metaphors}

\subsection{Personalized Temporal Metaphors}

In virtue of the 'Pan-human beings' experience foundation', the temporal metaphors in English and Chinese have features in common. For example, both the two languages adopt personification to describe time in daily life. For instance, Time is the greatest professor, 时间是最伟大的导师; Time is the greatest teacher, 时间是最好的老 师; Time is the father of truth, 时间是真理之父; Time and I against any two, 携手时间，一人抵两.

Both English and Chinese are likely to adopt characteristics and motions of people and endue it with human being's features and behaviors. For example, there are common sayings like Time waits for no man. and 时不我 待。. Other examples are like Time abandons the one who abandoned him. and 抛弃时间的人,时间也抛弃他。; Time will tell and 时间能够证明一切。; The time slipped by. and 时间悄悄地溜走; as long as time permits and 只要时间允许的话。; Time undermines us and 岁月暗中催人老. Here time is seen as with the ability to “wait”, "abandon", "slip", "permit" and "undermines" just like humankind who has spirit, life and action.

However, there is no denying that the differences between the English nation and the Chinese nation in association and rhetoric cause the differences in concrete techniques of expression. Time as an abstract concept, can be endowed with personalized behaviors vividly with ample verbs in English, but it is not the same case in Chinese. There are popular expressions like fool away one's time (虚度时光); kill time（消磨时光）; fritter time away (挥霍时间); murder time (浪费时间) and cheat time (消耗时间) and sentences like Time is life and when the idle man kills time, he kills himself. (时间就是生命, 懒人消耗时间就是消耗自己的生命。) and Don't fool away your time in public houses. (不要把你的时间浪费在酒吧里。) Yet, it is more common to materialize time as objects in Chinese phrases like 挤时间 (“try and find time”), 抓紧时间 (“save time”), 把握时间 (“make well use of time") and 争分夺秒 (“make every minute count"), just like the corresponding Chinese translations of the example phrases above, which demonstrate that time is regarded as objects in the space. Other sentences examples like: Time is a file that wear sand makes no noise. (光阴如锉,细磨无声); Time works wonders. (时间 的效力不可思议); Tomorrow never comes. (明天无尽头); Time reveals all things. (万事日久自明).

\subsection{Materialized Temporal Metaphors}

One of the representative thinking modes of the earlier people is the embodiment activities. That is to take the body as the standard to measure the surroundings. For example, the human beings cognize their own organs-eyes before making use of them to refer to objects' parts like eye needle and further to refer to abstract concept-eye of the soul. The way for representing the abstract concept with concrete and tangible surrounding objects is the materialized metaphor. This type of metaphor is in accordance with the self-centered cognitive rule which is from the near to the distant, from the concrete to the abstract and from the simple to the complex. Similarly, the abstract and intangible concept of time is taken as an object. The temporal metaphor interlinks English and Chinese. For example, Time is life (时间就是生命。).

Both in English and Chinese, time is regarded as important things, so people get used to describing time with familiar concepts in daily life. The most representative example in English is Time is money, which can be reflected in the following common example: How do you spend your time last weekend?; You are wasting my time.; I have invested a lot of time in this case. and I cannot afford the time. From the above example we can see, they imply three conceptual metaphors which contain each other: 'time is money'; 'time is a limited resource' and 'time is a valuable commodity'. These three conceptual metaphors utilize the popular concept of money in people's mind and form a conceptual system related with 'time'. In Chinese, there are also expressions like 一寸 光阴一寸金, 寸金难买寸光阴。(“An inch of time is an inch of gold.”); 要珍惜时间, 不要浪费时间。 (“Please cherish the time and do not waste it.") and 你要抓紧时间, 好好学习。 (“Grasp the time and work hard.").

This measure expounds vividly the preciousness and finiteness of time, deriving a great many expressions. In the two languages, time both can be seen as material objects and reflects their properties as objects. For example, people 'save time' (节省时间), 'budget' time (安排时间), 'spend'time (花费时间) and 'waste'time (浪费时间). Time also can be 'measured', 'colored', such as in expressions like for a long time (长时间), for a short period of time (短时间) and the golden age (镀金时代); thus midnight (半夜) is derived with the separation of the length of time. In the temporal metaphor for age, length can be used to express the life span in both English and 
Chinese, for example, short lived in English and 短命 in Chinese. However, Chinese employs “高' (“high”) and “低” (“low”) to express the age, like phrases 高寿 (“longevity”) and 低龄化 (“lowering trend of age”), while in English 'high' and 'low' are never connected with temporal concept. The distinction is related with the tradition of respecting elders and putting them in a high social status in Chinese culture.

As both English and Chinese generally compare time with valuable resources, for example, Time is money. (时间 就是金钱。) and Time is treasure. (时间就是财富。), we can see that the two cultures all cherish time greatly. The difference lies that although there are such expressions in the modern Chinese nowadays, the Chinese people cherish more of time than money. It is the sub-concept of metaphor that 'time is the finite resource' plays the main role while the elements of money and valuables are being weakened. The verb 花 ("spend") in the Chinese expression 花一天时间 (“spend a day”) can be alternatively replaced by word 用 (“use”). The idiom 一寸光阴 一寸金 ("An inch of time is an inch of gold.") is used to reflect the value of time which is the idea conceiving in it that the Chinese think more of. Therefore, compared with the English culture, the Chinese temporal metaphors relatively weaken the money concept in time.

It is noteworthy that there is a special metaphor in English, which compares time to 'sand', like in the famous saying sand in the hourglass. This is because reckoning the sandglass is an ancient timing method in English nations.

The passing of time is seen as the action or motion of the object for describing time's shortness and transience. For example, there are expressions Time flies like an arrow. (光阴似箭) both in the two languages.

The running water is a relatively distinctive image in Chinese as a metaphor to time. The time and the running water are common in characteristics that they are going on continually and gone forever. Chinese not only compares time to water, but also employs words with features of water to describe time, for example, 时间永是 流驶 (“Time is running forever.”), 街市依旧太平 (“Time flows eternally and streets are peaceful as before.”); 柔肠百转度流光 (“spend time with deep feelings”); 似水流年(“Youth passes as a fleeting wave.”) and 如果时 光能够倒流 (“if we can put the clock back"). Though there exist similar metaphors in English, like time flows like a river., objects with wings or legs are much more frequently used, for instance, Time has wings.; Seize the day, for fleeting youth never returns; Time lost never returns. .

There are also distinctive characteristics in Chinese materialized temporal metaphors, which cannot be found equal examples in English. A lot of set phrases in Chinese make use of the extracted features of animals and natural phenomena to metaphor time, such as 电光石火 (“anything that vanishes in a flash”), 白驹过隙 (“Time passes quickly like a white pony's shadow across a crevice.”), 窗间过马 (“Time is as short as a horse flashing past a window."), 过眼云烟 (“as transient as a fleeting cloud”), 物换星移 (“Things change with the passing of years.”), 沧海桑田(“Seas change into mulberry fields and mulberry fields into seas-time brings great changes to the world."), 冰冻三尺 ("It takes more than one cold day for the river to freeze three feet deep."), 海枯石烂 (“till the seas dry up and the rocks decay”). In this type of metaphor there are only tenors but no vehicles.

In Chinese, there is a special way to metaphor time, which is to replace the tenor with the vehicle by related association instead of by using the body directly. This is called melonymy. Though there is a similar way of expressions in English poets and novels sometimes, the metaphorical ways in Chinese are much more abundant. For example, the sceneries in different seasons in nature are represented in Chinese idioms to remind the reader of the corresponding seasonal time. There are expressions like 阳春烟景 (“a vast blur of mist and rain in spring”), 鸟语花香 (“twitter of birds and fragrance of flowers -an idyllic scene”), 桃红柳绿 (“The peach trees are in bloom and the willows are turning green.") to associate the spring; 艾绿蒲香 (“The wormwoods are turning green and the calamus are in aroma.”), 赤日炎炎(“The sun is shining fiercely.”) and 田月桑时 (“during the busy farming season”) to associate summer; 金风玉露 (“Autumn's Golden Wind embraces Dew of Jade.”), 草木黄落 (“Grass and trees wither.”) and 菊香蟹肥 (“Chrysanthemums are fragrant and crabs are fleshy.”) to associate autumn; 天寒地冻 (“The weather is cold and the ground is frozen.”), 寒风凛洌 (“The wind nips hard."), 冰天雪地 (“the world of ice and snow") to associate winter.

Another representative vehicle in materialized temporal metaphors is 'container'. People are objects independent from the surroundings, so their bodies can be seen as containers with inside and outside. Such a concept is projected into other objects in the surroundings like houses, boxes, trees and the abstract time. Time is boundless, but we can see the comparative boundary and depth through the metaphor of container. For example, by the end of last year, we had finished half of the project. (去年年末, 我们已经完成了工程的一半); From 2000 to 2010 , he was living in the New York city. (从 2000 年到 2010 年, 他一直住在纽约市); She was lost in her happy past time. (她沉浸在过去的美好时光中). 
Last but not least, people get used to taking their own bodies as the measurement to the surroundings, thus the temporal metaphor forms by projecting the cognition of the human body to the time. This type of metaphor with the human body as the vehicle is rich in Chinese, which usually expresses temporal concepts with the structure 'parts of human body+localizers'. For example, words 目前, 眼前, 面前, 手头上, 眼下 emphasize the fact that the present time is close to the observer's body. Thereby, many temporal metaphors are derived to describe the emergency such as 迫在眉睫 (“be hanging over one's head"), 一眨眼 (“at the eye wink"), 千钧一发 (“a hundred weight hanging by a hair") and 火烧眉毛 (“Fire catches the eyebrows."). Johnson-Laird named such an image as "the schema that is pregnant in the body" (Johnson-Laird, 1976, P.37). By contrast, this type of metaphor is rarely seen in the English language.

\subsection{Event Temporal Metaphors}

During the long-time productive practice and experience, some abstract events, activities, behaviors and states that happen in a specified time point are 'abstracted' and projected into the temporal concept. Some of these temporal representations were kept up for special historical events or traditional customs. For example, in English 'Ascension Day' was derived from the day when Jesus ascended to the heaven in Christianity; 'St. Valentine's Day' was derived from February $14^{\text {th }}$ in the $3^{\text {rd }}$ century when the disciple St. Valentine suffered the death by martyr. In Chinese, 元宵节(“the Lantern Festival")is on January $15^{\text {th }}$ on the lunar calendar, in which ‘元' was from the specified time point called 'Shangyuan' in ancient China and '宵' was from the meaning of 'night'. Other examples are like 端午节 (“the Dragon-boat Festival”) and 清明节 (“the Tomb Sweeping Day”).

Certain time point formed through activities in people's developmental process which are worth commemorating. These events are given the function to refer to temporal points. For example, in the Western society 'circumcision' of Judaism refers to the ritual to the newborn on the $8^{\text {th }}$ day after its birth. In Chinese, there are similar temporal points, for example, 诞生礼 (“the birthday ceremony”), which means the celebration to the newborn from the relatives so as to drive out evil spirits for the mother after the delivery. Other examples are like 剃头礼 (“head shaving ceremony”), 抓周礼 (“lots drawing ceremony”), 成丁礼 (“coming of age ceremony”) and so on. These etiquettes and customs shaped images gradually in people's mind and were linked with the temporal concepts unconsciously. There is also addresses to ages in the ancient Chinese like 总角 (“a child's hair twisted in a knot in childhood"), 束发 (“hair tied up around the age of fifteen”) and 弱冠 (“hat crowned in the coming of age at twenty”). “束发” refers to teen-agers because in the traditional customs males wore hair in a bun on the top of the head when they reached manhood. Such a behavior was operated repeatedly and formed the projection to the temporal map.

There is another type of temporal representations formed in the reference of people's productive activities or natural phenomena, which only turns up in the Chinese language. For example, the ancient Chinese people measured time with twelve divisions of the day and night including 子 (“Zi"), 丑 (“Chou”), 寅 (“Yin”), 卯 (“Mao”), 辰 (“Chen”), 已 (“Si”), 午 (“Wu”), 未 (“Wei”), 申 (“Shen”), 西 (“You”), 戌 (“Wu”) and 亥 ("Hai"). Later in the Han dynasty, 'traditional twelve two-hour periods' was employed, in which 子时 ("the mouse time") refers to 'the period of the day from 11 p.m. to 1 a.m.' when mouse begin activities; 丑时 (“the cow time") refers to 'the period of the day from 1 a.m. to 3 a.m.' when the cow finishes the graze and begins to plough; 人定 (“mid-night”) which means 'people retire' refers to 'the midnight'.

In addition, Chinese language is likely to regularize the time of conventional behaviors or activities and employ it as temporal measurements. For example, Chinese phrases like 一碗茶的功夫 ("the time for drinking a cup of tea”), 一支烟的功夫 (“the time for smoking a cigarette”), 打个盹的功夫 (“the time for dozing off”), 撒一脬 尿的功夫 (“the time for urinating”) and 一炷香的功夫 (“the time for burning a stick of incense") are used to refer to the duration of time that activities-'drinking a cup of tea', 'smoking a cigarette', 'dozing off', 'urinating' and 'burning a stick of incense' spend. These temporal references are inaccurate and sometimes even symbolic and imaginary, for instance, 一转眼的功夫 (“in the batting of an eye lid"), 是花一现 (“flower briefly as the broad-leaved epiphyllum"), which utilize behaviors of 'the twinkling of an eye' and 'an epiphyllum oxypetalum vanishing as soon as it appears' to refer to a short moment. While in English, though there are always exaggerated temporal expressions like I have been waiting for you for a hundred years. , there are no temporal metaphors that project events into the time durations.

From above, it is obvious that Chinese is much richer than English in temporal metaphors derived from events and activities in daily life.

\subsection{Abstracted Temporal Metaphors}

The abstracted temporal metaphors mean that the vehicles in the metaphors are turned to be abstract and immaterial concepts instead of concrete images. For example, there is a sentence extracted from the novel $A$ Tale 
of the Two Cities by Charles Dickens: "It was the age of wisdom; it was the age of foolishness, it was the epoch of belief; it was the epoch of doubtfulness, it was the season of light; it was the season of darkness; it was the spring of hope, it was the winter of despair." (这是智慧的年代, 这是愚蛀的年代; 这是信仰的时期, 这是怀 疑的时期; 这是光明的季节，这是黑暗的季节; 这是希望之春，这是失望之冬。）Here, the abstract concept 'time' is compared by a series other abstract concepts- wisdom, foolishness, belief, doubtfulness, light, darkness, hope and despair. This metaphoric way is usually employed both in the English and Chinese poets and literary works.

Time also can be abstracted into emptiness of images, which are set up highly over us but do not exist in fact. For example, in English there are popular sayings like: Time tries truth.; Time consecrates: what is gray with age becomes religion. ; Time tries all. Here time is raised to the status as the same as God with the ability to test people. Other examples like: Time brings the truth to light. ; Time is the Father of truth. In modern Chinese, there are similar expressions 经受时间的考验 (“stand the test of time"), 经过时间的洗礼 (“experience the trail of time"), which are probably borrowed from the English culture. It demonstrates that both the two nations perceived and realized the mysterious power of time and put it in a high place.

\subsection{Colorized Temporal Metaphors}

The colorized temporal metaphors refer to taking hues as vehicles to signify the specified temporal concepts. This temporal metaphorical type is widely employed in Chinese, for example, 红色的年代 (“the red times"), 黑暗的年代 (“the dark times”), 青春年华 (“the green times”), 金色年华 (“the golden times”). In comparison, English also has similar expressions of colors like the dark times, the golden age, but which are more tenuous. Usually the corresponding English translations do not involve tints, for instances, the revolutionary days (红色的 年代) and the youthful years (青春年华). The most classical example is the famous music composed by Rezső Seress-Gloomy Sunday, which was translated into Chinese as 黑色星期天 (“the Black Sunday”).

Even in modern times, Chinese are still high on forming new words with colorized temporal metaphors to signify specified events according to the new trend of the society. For example, in 2005, a great many newspapers and web sites described that the jewellery industry in China enters into 'the white times', which means that white metals including platinum and silver were overwhelmingly favored in these days. Today, the phrase 灰色时代 (“the gray times”) is used to satirize the severe air pollution; while 绿色时代 (“the green times") refers to the times when environment protection is greatly concerned in food, clothing shelter and transportation.

\subsection{Allusion Temporal Metaphors}

Allusion temporal metaphors mean citing literary quotations or allusions from the classics or ancient works to metaphor the temporal concepts. It is a unique usage with Chinese characteristics. For example, 而立之年 (“thirty years of age”), 不惑之年 (“forty years of age”), 天命之年 (“fifty years of age”) are all originated from the Analects of Confucius; 古稀之年 ("seventy years of age") is originated from the poem written by $\mathrm{Du}$ $\mathrm{Fu}$ : 人生七十古来稀 (“A man seldom lives to be seventy years old.”). This is bound to the social situation in ancient China, when people could hardly live up to the age of seventy for the poor living and medical conditions. 豆冦年华 (“a maiden thirteen years old”) is originated from the poetry of the Tang Dynasty-Set Off: “娉娉裒裒 十三余，豆冦梢头二月初。” “"She is pretty and not yet to fourteen, like the young spring-tip of a cardamon in early spring.") . Another example is a verse composed by the famous ancient Chinese poet Tao Yuanming in Zezi (责子)- “阿宣已二八, 懒惰故无匹。阿舒行志学, 而不爱文术。” ““A Xuan had been fifteen but was not willing to study.”). Here the word “志学” refers to the age “fifteen', which is derived from Confucius' words: “吾十有五 而志于学。” (“Since the age of fifteen, I have devoted myself to learning."). This temporal metaphor conceives double meanings, pointing out that the son of Tao had reached fifteen but was not willing to study. There are also proverbs like 说曹操曹操到 (“Speak of Caocao, he comes.") to describe the moment when 'Speak of the devil, and he appears'. The saying is derived from the historical story that in the emergency when the Emperor Xian of Han was pursuit and attacked by the rebel armies, someone nominated Caocao who was the only person that had the capability to save the emperor. In grave danger the reinforcement of the General Caocao arrived and put down the rebellion. The idiom 千钧一发 (“a hundred weight hanging by a hair”) refers to a crucial and emergent moment. It is out of the poem in the Book of Former Han: “夫以一缕之任, 系千钧之重, 上悬无极之高, 下 垂不测之渊, 虽甚愚之人, 犹知哀其将绝也。” (“Although I am clumsy, I know the danger to tie a hundredweight to a thread up to the topless sky and down to the bottomless abyss."). As early as in Tang Dynasty, the well-known man of letters Han Yu quoted the metaphor in The Letter to Meng Shangshu: “其危如一发引千 钧” (“It is so emergent like a hundred weight hanging by a hair."). Similarly, 弥留之际 (“the moment when someone is laying die") means the time when the one is terminally ill and at his or her last gasp, which is derived 
from the quotation in Shang Shu (The book of History): “病日臻, 既弥留。” (“The illness is growing worse day by day and his time is close at hand.").

The enthusiasm of Chinese to employ allusion temporal metaphors suffered no loss in today. By contrast, although there are a lot of allusion rhetorics in English, it is difficult to find any expressions of quotation temporal metaphors. It is caused by the conservatism in Chinese culture and different aesthetical standards in the two cultures (Lian, 2002), which will be analyzed elaborately in the following passage. In Chinese, the more quotations are used, the more literary elegance is displayed. However, in English, too many quotations only show the writer's bankruptcy of the original ideas, even would be probably involved in plagiarism.

\section{Cultural Enlightenments from English and Chinese Temporal Metaphors}

From the above analysis, we can see that English and Chinese have commons on the temporal metaphors representations, especially in "Personalized" and "Materialized" aspects. It is these basic "pan-human experiences' that give nations with different cultures the opportunity to communicate with each other and learn from each other, and produce the possibility to realize the globalization. Due to the various factors including natural environment, historic background, values, beliefs, world outlooks, customs, thinking modes in different cultures, metaphorical representations that stand for the same concept in different languages are realized in diverse measures. These differences in temporal metaphor concepts and representations provide a platform for us to have a clear and objective awareness of ourselves, so as to obtain references from the Westerners' strong points and close the gap.

Firstly, the 'annular' temporal concept in Chinese culture treats time as a circle that goes round and begins again. This standpoint makes people believe that the lost things can be regained and the destroyed things can be repaired with the time lapse, which is reflected in the popular saying “失之东隅, 收之桑榆。”(“The loss suffered earlier can be made up for later."). (Originated from the history of Later Han, Biography of Feng Yi) People are satisfied with the existing state and reluctant to move forward with expectations for getting a break. Thus, leisureliness becomes one of the most important features of Chinese small farming economy. On the one hand, this type of 'annular' temporal concept promotes the self-cultivation and social stability and forges the Chinese national quality with tolerance and diligence; on the other hand, the idea of samsara fostered the passive and negative life attitude and nourished the deep-rooted servility. Therefore, we should draw on the 'linear' temporal concept of the Westerners, realize the transience of time soberly and keep the sense of urgency, and do the things that we aspire to do bravely.

Secondly, the 'past' temporal concept in Chinese culture makes people dwell in past time, respect the ancestors and the seniors and advocate classical experiences and doctrines. On the one hand, this temporal trend is favorable for inheriting the traditional helpful experience and lessons from the history to give enlightenment and guidance to today's society and for developing the insistence to the faith. Moreover, it is favorable for cultivating the sense of national pride and cohesive force, and preserving the Chinese cultivation on the glory trail for long years. On the other hand, this type of temporal trend stresses on the comparison of events diachronically, thus lacks the synchronic reference of the other nations and the information of the new times, which would immerse people into the glorious past time and the satisfaction from the renascence; and focus on the past experiences but ignore the thoughts and plans to the future. People are probable to cling conservatively to the old system, stay in lethargy and seek no progress, and lock the doors from the world. Actually, we have had such bitter experiences in our history. In the present-day society with the trend of globalization and cut-throat competition, this kind of view point is hardly able to catch up the developing pace of the world. So we should learn the 'future' temporal trend from the Westerners to keep the view on the future, striving to promote the development of the society with positive innovation and active exploitation. Furthermore, this 'future' temporal trend is apt to make the synchronic comparison at the lateral spatial level, which helps people to overcome their own disadvantages and make progress.

Thirdly, the 'vague' temporal concept in Chinese culture attaches importance to the qualitative judgment of the time concept, which gives more flexibility and fluctuation in the daily communications on the one hand. On the other hand, it connives at unpunctuality and wastes the precious time on long-time waiting, which is in a conflict with the modern concept of high efficiency. All professions and trades nowadays have high requirements on punctuation, for one minute's lateness could cause great losses. Therefore, we should learn the 'exact' temporal concept from the Westerners and get into the habit and realization of punctuation.

The traditional Chinese temporal metaphor concepts are the products of the culture and language with thousands of years' history in China. We have the responsibility to keep it and inherit it from generation to generation. However, the society is changing continuously and we are incapable to go against the trend. It is inevitable that 
some of the traditional elements display their limitations in a specific period. What we should do is not to retreat from the reality and close our door, but to transform positively to keep up with the times. Especially in the current situation where the Western world takes up the dominant place in economy, it is an emergency to take in their advantages and make these strong points work for us. As to those unavoidable cultural fusion phenomena, we shall show our tolerance and observe the natural and social law of development so as to enhance China's modernization steadily and positively.

\section{Conclusion}

From the above analysis, we can see that English and Chinese reflect both similarities and differences in 'personalized temporal metaphors', 'materialized temporal metaphors', 'event temporal metaphors', 'abstracted temporal metaphors', 'colorized temporal metaphors' and 'allusion temporal metaphors'. "Language cannot live without culture" (Sapir \& Irvine, 2002, P.56). Temporal metaphor is not only a language phenomenon, but more of a cultural reflection. Therefore, it would make our contrastive study deeper and more comprehensive from a cultural perspective.

\section{References}

Johnson-Laird, P. N. (1976). Language and Perception. Massachusetts: Belknap Press.

Lakoff, G. (1990). The Invariance Hypothesis: Is Abstract Reason Based Image-schemas? Cognitive Linguistics, 1, 39-47. http://dx.doi.org/10.1515/cogl.1990.1.1.39

Lakoff, G. (1993). The Contemporary Theory of Metaphor. Cambridge: Cambridge University Press.

Lakoff, G., \& Johnson, M. (1999). Philosophy in the Flesh: The Embodied Mind and Its Challenge to Western Thought. New York: Basic Books.

Lakoff, G., \& Johnson, M. (1980). Metaphors We Live by. Chicago: University of Chicago Press.

Lian, S. (2002). Chinese and Western Ways of Thinking. Foreign Languages and Their Teaching, 2, 40-46.

Sapir, E., \& Irvine, J. (2002). The Psychology of Culture: A Course of Lectures. Berlin: Walter de Gruyter. http://dx.doi.org/10.1515/9783110889468

\section{Copyrights}

Copyright for this article is retained by the author(s), with first publication rights granted to the journal.

This is an open-access article distributed under the terms and conditions of the Creative Commons Attribution license (http://creativecommons.org/licenses/by/3.0/). 